\title{
UM NEGÓCIO NA INTERNET BOM PRA CACHORRO
}

\author{
Marília Castelo Branco Araújo - Universidade Estadual do Ceará ${ }^{1}$ \\ Aline de Assis Teixeira - Universidade Estadual do Ceará ${ }^{2}$ \\ Ana Augusta Ferreira de Freitas - Universidade Estadual do Ceará ${ }^{3}$
}

Resumo: O campo virtual vem gerando oportunidades de negócios. Este contexto torna-se atrativo para empreendedores. Este caso trata dos desafios enfrentados por dois jovens empreendedores que vislumbraram uma oportunidade e montaram um negócio na internet. Por meio de elaboração e análise própria de um Plano de Negócios, o segmento pet foi confirmado como um ramo de atuação promissor. Inicialmente, o negócio foi constituído como um portal sem fins lucrativos. Após conquistar a visibilidade e o número de acessos suficientes para atrair um maior número de clientes, o portal deverá constituir-se legalmente como empresa e auferir lucros. O principal problema envolve o desafio para o crescimento. O caso tem como objetivos de aprendizagem: examinar as estratégias de marketing digital e analisar as estratégias empreendidas para a inserção de um novo negócio na internet. Este estudo deve ser aplicado a alunos dos cursos de graduação e especialização em administração e marketing em forma de debate em sala de aula, visando atrelar seus conhecimentos teóricos a situações práticas vivenciadas por gestores de empresas. A situação relatada partiu de um caso real, ocorrido em 2011, com coleta de dados primários obtidos através de técnicas de observação e entrevistas com os idealizadores do projeto e também pela coleta de dados secundários que embasaram as alternativas para a análise do caso.

Palavras-chave: Caso de ensino, Marketing Digital; Estratégias de Crescimento.

\section{A PRETTY GOOD BUSINESS}

Abstract: The virtual field is generating business opportunities, leaving entrepreneurs to choose a niche market to serve and formulate strategies to reach their audience. This case deals with the challenges and dilemmas faced by two young entrepreneurs who

\footnotetext{
${ }^{1}$ Email: mariliacb2008@gmail.com

${ }^{2}$ E.mail: alinedeassisteixeira@gmail.com

${ }^{3}$ E.mail: freitas8@terra.com.br Endereço: Av. Dr. Silas Munguba, 1700, Campus do Itaperi, CEP: 60.714 .903 - Fortaleza-CE
} 
saw an opportunity and built a business on the internet. Through proper analysis and preparation of a Business Plan, the pet segment was confirmed as a promising line of work. Initially, the business was incorporated as a nonprofit website. After winning the visibility and number of entries sufficient to attract a greater number of customers, the portal should become legally as a company and earn profits. Facing problem is concerned with growing strategies. Learning objectives are: examining the digital marketing strategies and analyze the strategies undertaken for the insertion of a new business on the internet. This study should be applied to students of undergraduate courses and expertise in management and marketing as a discussion in the classroom in order to tie their theoretical knowledge to practical situations experienced by business managers. The situation reported came from a real case that occurred in 2011 , a collection of primary data obtained through observation techniques and interviews with the creators of the project and also the collection of secondary data that supported the alternatives for the analysis of the case.

Keywords: Teaching Case; Digital Marketing; Growth Strategies.

\section{Surge um novo mundo: a oportunidade}

Em meados de junho de 2010, João Paulo Assunção estudante de Administração e interessado em aplicar os conhecimentos adquiridos no curso, vislumbrou a oportunidade de iniciar um negócio na internet. Aproveitando sua paixão por animais, principalmente por cães, seus conhecimentos em Administração e habilidades em informática, decidiu convidar seu irmão, graduado em computação e com experiência na área de desenvolvimento de sistemas, para iniciarem um portal voltado para a venda de publicidade para empresas do segmento pet.

Antes de pensar em ingressar no curso de Administração, João Paulo já tinha interesse e desejo em trabalhar com animais. O negócio, dessa forma, também possibilitaria a realização deste sonho, o que lhe trouxe novas expectativas. No entanto, os irmãos sabiam que só seu interesse pelo ramo pet não garantiria o sucesso do seu negócio. Por isso, antes de começar as atividades do empreendimento, elaboraram um plano de negócios para analisar a viabilidade do projeto.

ARAUJO, M. C. B.; TEIXEIRA, A. A.;FREITAS, A. A. F. Caso de ensino: Um negócio na internet bom pra cachorro. Revista de Empreendedorismo e Gestão de Pequenas Empresas, v.2, n.3, 2013. 
A oportunidade surge em função de evidências de que este tipo de negócio poderia ser um lócus adequado para investimentos. Segundo pesquisas de indicadores de mercado da IAB BRASIL: a mídia digital interativa cresceu 28,85\% (Jan a Nov/09 x Jan a Nov/10). Continua sendo a mídia que mais cresce em investimento, número de pessoas e tempo de acesso. Em 2010, 73,7 milhões de pessoas acessaram a internet, confirmando a potência da rede como um meio eletrônico de massa. Estimativas apontam que ao final de 2011 , os investimentos em mídia irão crescer $25 \%$, representando 1,55 bilhões de reais em publicidade online (IAB BRASIL, 2010).

Em relação ao segmento pet, a Radar Pet 2009 - pesquisa encomendada pela COMAC (Comissão de Animais de Companhia) do SINDAN (Sindicato Nacional da Indústria de Produtos para Saúde Animal) afere uma população de cerca de 25 milhões de cães no Brasil, presentes nas residências das classes A, B e C. Os dados confirmam a preferência por cães, $79 \%$ das escolhas, como animais de estimação. A pesquisa foi feita com o intuito de acompanhar os hábitos e as tendências dos proprietários de pets brasileiros.

O segmento pet, mercado de produtos e serviços para animais de estimação, cresce $12 \%$ a nível mundial, movimentando cerca de US\$ 65 bilhões por ano, segundo pesquisa publicada pela Euromonitor International. O Brasil ocupa a segunda posição no ranking mundial deste segmento e movimenta mais de US\$ 9 bilhões por ano entre alimentos, medicamentos, higiene, estética, centros de adestramentos e hotéis. (EUROMONITOR 2002, apud PALMA, 2002).

Outro dado a ser considerado é que, com o envelhecimento da população e o aumento de pessoas que vivem sozinhas, os animais passaram a ser considerados como membros da família. Esse fenômeno tem sido chamado de humanização dos animais e isso tem influenciado o mercado de produtos e serviços ligados aos animais domésticos. Segundo Viotto (2009, p.2), "o estilo de vida do consumidor brasileiro mudou nos últimos anos, o número de pessoas vivendo sozinhas e o envelhecimento

ARAUJO, M. C. B.; TEIXEIRA, A. A.;FREITAS, A. A. F. Caso de ensino: Um negócio na internet bom pra cachorro. Revista de Empreendedorismo e Gestão de Pequenas Empresas, v.2, n.3, 2013. 
da população são fatores que contribuem para a expansão deste mercado." Desse modo, proprietários têm se interessado cada vez mais por informações relacionadas aos seus pets. Também foi considerado que, segundo pesquisa IBOPE, há um crescente aumento do tempo de navegação de vídeos online, 24,8 milhões de pessoas navegam em sites de vídeos; representando 68\% dos usuários ativos (na base domiciliar), e do acesso a redes sociais, $86 \%$ das pessoas que acessam internet utilizam redes sociais (IAB BRASIL,2010).

De acordo com a pesquisa realizada pelo CETIC.br (Centro de Estudos sobre as Tecnologias da Informação e da Comunicação, 2009), o brasileiro é o maior usuário em termos de tempo e conexão, e também é o mais bem relacionado, o que demonstra a utilização da internet como um elemento de socialização. Desse modo, a instauração de um sistema com vídeos, fórum e rede social tornou-se fundamental para atrair um maior número de usuários. Ainda sobre os dados captados pelo CETIC.br, destaca-se também o crescimento da atividade de pesquisa sobre bens e serviços realizada na internet, que passa de $50 \%$, em 2008 , para $62 \%$ do total de usuários de Internet, em 2009. Assim, como o número de pessoas que utilizam a internet é grande e tende a aumentar, as mídias digitais tornam-se meio fundamental para divulgar produtos e serviços.

Os resultados não foram surpresa para João Paulo, que sempre esteve antenado na área cinófila. Além de poder comprovar suas suspeitas de que seria vantajoso investir no ramo pet, o plano de negócios permitiu uma melhor visão e análise de todos os fatores, internos e externos, relacionados ao negócio. Como consequência da pesquisa de mercado realizada, puderam ser observados os costumes $e$ as preferências do internauta brasileiro e com isso os sócios puderam definir a estrutura e conteúdo do sistema. Dessa forma surgiu o portal 'Mundo C'. Trata-se de um portal, espécie de site mais dinâmico, que oferece um ambiente virtual com informações e entretenimento aos seus usuários, contando com notícias, artigos, entrevistas, vídeos,

ARAUJO, M. C. B.; TEIXEIRA, A. A.;FREITAS, A. A. F. Caso de ensino: Um negócio na internet bom pra cachorro. Revista de Empreendedorismo e Gestão de Pequenas Empresas, v.2, n.3, 2013. 
rede social, loja virtual, agenda de eventos, sistema de busca de serviços pet, sistema de adoção e vendas e fórum. Todo o conteúdo do portal é atualizado diariamente. A intenção da construção do negócio é tornar-se uma empresa do ramo de prestação de serviços de publicidade digital, por meio de divulgação em meio eletrônico (espaço fixo do portal) através de banners publicitários de pessoas físicas ou jurídicas que atuam direta ou indiretamente no mercado pet, mais precisamente com cães.

O "Mundo C" foi criado justamente para suprir as necessidades de divulgação das empresas do ramo pet. Tendo em vista que, a publicidade permite o conhecimento da marca pelo cliente e estimula a demanda de produtos e serviços, o investimento dirigido à divulgação gera resultados positivos comprovados.

Para atrair usuários, os proprietários do "Mundo C" acreditam que a inovação e criatividade devem estar sempre presentes. Os sócios relatam que uma das ações de maior sucesso foi a Loja Virtual, com disponibilização de produtos sem cobrança de taxas para quem possui uma conta no portal. Tal serviço, segundo eles, é inédito no mercado e funciona como uma espécie de jogo. A Loja Virtual do "Mundo C" disponibiliza uma série de produtos e serviços para cachorros. A cada atividade de participação no portal (postar comentários e fotos, adicionar amigos, participar de comunidades), os usuários têm a oportunidade de acumular moedas e trocá-las pelos produtos e serviços da Loja Virtual.

A Loja Virtual mantém sistema de parcerias com organizações do segmento que disponibilizam seus produtos gratuitamente para o portal em troca de divulgação de sua marca no local. Os sócios avaliam que, desse modo, é possível atrair e manter maior quantidade de usuários e conseguir proximidade com empresas do ramo. A realização de sorteios e concursos também está sempre presente no portal como forma de gerar maior atratividade. A adesão à proposta tem crescido ao longo do tempo. Após a obtenção de dados favoráveis por meio da análise do mercado, os sócios elaboraram uma estrutura interna das atividades e estratégias pertinentes ao empreendimento.

ARAUJO, M. C. B.; TEIXEIRA, A. A.;FREITAS, A. A. F. Caso de ensino: Um negócio na internet bom pra cachorro. Revista de Empreendedorismo e Gestão de Pequenas Empresas, v.2, n.3, 2013. 
Dessa forma, o negócio criado parece estar inserido em um mercado promissor e estratégico. No entanto, os sócios ainda vivem o desafio sobre as melhores formas de crescimento do negócio.

\section{A realidade da informalidade}

Segundo o Serviço Brasileiro de Apoio às Micro e Pequenas Empresas (SEBRAE), a formalização pode representar oportunidades como o fechamento de parcerias, o acesso a linhas de crédito, a exportação e o recebimento de subsídios do governo. Além disso, o SEBRAE orienta que a informalidade é um risco para o empreendedor, que pode ter suas mercadorias apreendidas pelo poder público e tem limitadas possibilidades de crescimento e divulgação. Os sócios estão cientes dessas oportunidades e riscos, entretanto, a empresa ainda se encontra na informalidade. Não há também uma estrutura física própria do empreendimento, sem escritório e equipamentos próprios. Os sócios trabalharam em suas residências, com seus equipamentos pessoais. Há reuniões semanais para análise de situação setorial e discussão geral sobre o negócio.

\section{Criatividade e inovação}

Assim, o "Mundo C" busca se diferenciar no mercado de publicidade online com foco no segmento pet através da manutenção de um portal inovador, sendo reconhecido pela qualidade e melhoria contínua. Quanto às formas de divulgação, o portal trabalha por meio de redes sociais (Orkut, Facebook, Twitter), canal no You Tube, participação em blogs, blog próprio, fixação de cartazes em empresas do segmento, participação em eventos locais e formação de parcerias para realização de eventos próprios locais.

ARAUJO, M. C. B.; TEIXEIRA, A. A.;FREITAS, A. A. F. Caso de ensino: Um negócio na internet bom pra cachorro. Revista de Empreendedorismo e Gestão de Pequenas Empresas, v.2, n.3, 2013. 


\section{Desejamos crescer. Mas como?}

Os sócios já têm planejada toda a gama de produtos que pretendem oferecer a partir do portal, que disponibilizará oportunidades de divulgação por meio de banners, imagens publicitárias inseridas em uma página do portal e que funciona como link para o site do anunciante, e um destaque no sistema de busca de serviços pet, responsável pela localização de profissionais do ramo.

Entre os serviços que os sócios planejam oferecer estão a emissão de relatórios com os levantamentos estatísticos sobre quantidade de acessos ao portal, cadastros, atualizações e demais assuntos relevantes para que o cliente possa acompanhar o seu investimento com segurança e de modo transparente.

O maior problema enfrentado pelos sócios, no entanto, é descobrir como alcançar o cliente, que tipo de estratégia usar para captá-los, sabendo que o empreendimento possui poucos recursos financeiros e humanos. Milhares de e-mails são enviados diariamente, para que empresas participem da Loja Virtual enviando seus produtos em troca de publicidade gratuita no local, mas a taxa de resposta ainda é baixa.

Entre os questionamentos vislumbrados pelos sócios estão: já que o negócio está inserido na internet, que permite diversas facilidades e comodidades, é possível estabelecer contatos e vínculos com empresas mesmo a longas distâncias? Além dos serviços de publicidade, que outros serviços poderiam ser oferecidos? Neste último ponto aparece a discussão sobre a possibilidade de viabilizar o comércio pela internet no ramo escolhido. O e-commerce tem crescido no Brasil, em função de vários fatores como: a democratização do acesso à internet, a expansão do crédito facilitado através de cartões de crédito e a expansão da classe C no Brasil (NASCIMENTO, 2011). No entanto, também é conhecido que nem todo produto comercializado na internet tem a

ARAUJO, M. C. B.; TEIXEIRA, A. A.;FREITAS, A. A. F. Caso de ensino: Um negócio na internet bom pra cachorro. Revista de Empreendedorismo e Gestão de Pequenas Empresas, v.2, n.3, 2013. 
mesma atratividade de compra para o cliente do que em lojas físicas e essas são algumas dúvidas que assolam os futuros empresários.

\section{Resumo do caso}

Este caso trata dos desafios enfrentados por dois jovens empreendedores que vislumbraram uma oportunidade e montaram um negócio na internet. Por meio de elaboração e análise própria de um plano de negócios, o segmento pet foi confirmado como um ramo de atuação promissor. Inicialmente o negócio foi constituído como um portal sem fins lucrativos. Após conquistar a visibilidade e a quantidade de acessos suficientes para atrair um maior número de clientes, este deverá adquirir forma jurídica, constituir-se legalmente como empresa e auferir lucros. No entanto, os empresários têm um problema em suas mãos: eles querem crescer, têm muitas ideias, mas também muitas dúvidas sobre quais as decisões mais acertadas para aumentar a base de clientes. Além disto, refletem a respeito de que tipo de cliente focar e que tipo de empresa seria necessário para atingir tais clientes. Criatividade, inovação e melhoria contínua já fazem parte do portal. Contudo, os sócios precisam tomar decisões administrativas importantes para dar prosseguimento ao empreendimento. Tendo em vista que o portal atua em âmbito nacional, possui poucos recursos financeiros e uma estrutura enxuta de funcionários, as principais dúvidas referem-se à prospecção de clientes e à viabilidade de investir em serviços de e-commerce.

\section{Caminhos a serem percorridos}

João Paulo percebeu uma oportunidade de negócios na internet e, com a ajuda do seu irmão Mateus, especialista na área, criou um portal voltado para o segmento pet com o intuito de posteriormente transformá-lo em uma empresa prestadora de serviços

ARAUJO, M. C. B.; TEIXEIRA, A. A.;FREITAS, A. A. F. Caso de ensino: Um negócio na internet bom pra cachorro. Revista de Empreendedorismo e Gestão de Pequenas Empresas, v.2, n.3, 2013. 
publicitários. O fato de o negócio estar inserido na internet traz muitas vantagens para empresários iniciantes, como a possibilidade de baixo investimento inicial, a não exigência de estrutura física, a flexibilidade do horário de trabalho. Contudo, como em qualquer outro empreendimento, estruturar um negócio na web também apresenta desafios.

Um dos principais conflitos enfrentados pelos sócios encontra-se na difícil tomada de decisão em relação ao aumento da base de clientes. Para um negócio que está inserido na internet, com abrangência a nível nacional, terceirizar seria realmente a melhor opção para comercializar produtos intangíveis, como é o caso do espaço publicitário que o portal disponibilizará?

Por experiência advinda da própria Loja Virtual do "Mundo C", João Paulo Assunção percebeu o quanto é complicado estabelecer laços com empresas apenas por meio da internet. As taxas de resposta aos convites eram baixas. Por outro lado, eram bem sucedidas as visitas a empresas locais, em que o próprio dono apresentava o portal e explicava os benefícios da parceria. Além de conseguir parcerias para a loja, conquistava também a confiança de futuros clientes. Contudo, como atingir clientes advindos de outros estados tendo escassos recursos financeiros e humanos? Caso optasse por terceirizar o serviço, como manter uma relação próxima com o cliente, que afinal deve ser o foco de qualquer negócio?

Outra questão importante a decidir é se o portal deverá aproveitar o espaço para implantar um e-commerce ou se dedicar apenas ao tipo de serviço que inicialmente estava proposto a realizar, no caso a venda de anúncios publicitários. Além disso, devem-se analisar os custos de comercialização, estoque, armazenagem e frete para verificar se realmente é vantajosa a transação comercial. Um dos aspectos que também merece ser levado em consideração é o fato de que dentre os principais clientes do "Mundo C" estão inclusos os pet shops, que seriam desfavorecidos com essa decisão do portal.

ARAUJO, M. C. B.; TEIXEIRA, A. A.;FREITAS, A. A. F. Caso de ensino: Um negócio na internet bom pra cachorro. Revista de Empreendedorismo e Gestão de Pequenas Empresas, v.2, n.3, 2013. 


\section{Objetivos de aprendizagem}

Este caso visa analisar as principais dificuldades para iniciar um empreendimento formal, bem como as oportunidades de realizar negócios na rede. $\mathrm{O}$ estudo tem como objetivos: 1. Examinar as estratégias de marketing digital; 2. Analisar as estratégias empreendidas para a inserção de um novo negócio na internet.

\section{Fontes dos dados}

O caso estuda uma situação real, enfrentada em 2011, por um portal sem fins lucrativos voltado para o mercado pet, especificamente cães, que busca ser formalizado e tornar-se lucrativo. As informações coletadas possuem caráter primário, obtidas por meio de técnicas de observação e entrevistas com os idealizadores do projeto, bem como caráter secundário, por meio de relatórios, pesquisas, artigos e livros que embasam as alternativas para a análise do caso.

\section{Sugestões para discussão do caso}

A proposta de aplicação desse caso é a geração de debates em sala de aula, que permitirão aos alunos dos cursos de graduação e/ou especialização em administração e marketing vislumbrar possibilidades e tomar decisões, atrelando seus conhecimentos teóricos a situações reais. Para fins didáticos e um melhor aproveitamento do estudo é interessante adotar algumas etapas para o processo: 1 . Explanação sobre a criação de novos negócios, com ênfase na internet; 2. Leitura individual do caso; 3. Discussão em pequenos grupos; 4 . Discussão em plenária e 5. Apresentação pelo professor da temática e da situação.

ARAUJO, M. C. B.; TEIXEIRA, A. A.;FREITAS, A. A. F. Caso de ensino: Um negócio na internet bom pra cachorro. Revista de Empreendedorismo e Gestão de Pequenas Empresas, v.2, n.3, 2013. 


\section{Questões do caso}

1. Atualmente o portal se configura como um portal sem fins lucrativos, embora tenha domínio de site, mas que pretende constituir-se como empresa e auferir lucros. a) Qual o momento ideal para realizar essa transformação, tendo em vista que é necessário ter atratividade não só para usuários, mas para clientes? b) Quais aspectos legais devem ser observados no processo de formalização?

2. Além da utilização da publicidade como fonte de receita para a futura empresa, seria viável a venda de produtos pelo portal? Vale ressaltar que pet shops também se enquadram como futuros clientes do portal.

3. Apesar de em pouco tempo de inserção no meio, o portal já contém um elevado nível de acessos mensais, contudo o mercado exige um maior número de visualizações. Dentro das limitações financeiras dos idealizadores, que estratégias de marketing digital seriam necessárias para tornar o portal mais acessado?

4. Devido às vantagens de acessibilidade proporcionadas pela internet, o portal já alcançou visibilidade nacional, portanto, caso a publicidade seja escolhida como meio de atuação da empresa, a contratação dos serviços do site, tornar-se-á interessante para anunciantes de todo o país. Nesse caso, quais seriam as melhores estratégias para a prospecção de clientes? Seria viável terceirizar os serviços de venda?

5. Mesmo restringindo seu nicho de mercado, especializando-se em cães, o portal atua no ramo de publicidade na internet, por isso apresenta vasta concorrência. Que estratégias o portal poderá utilizar não só para se inserir, mas para manter-se no mercado?

ARAUJO, M. C. B.; TEIXEIRA, A. A.;FREITAS, A. A. F. Caso de ensino: Um negócio na internet bom pra cachorro. Revista de Empreendedorismo e Gestão de Pequenas Empresas, v.2, n.3, 2013. 


\section{Respostas possíveis}

1. Atualmente o portal se configura como um portal sem fins lucrativos, embora tenha domínio de site, mas que pretende constituir-se como empresa e auferir lucros. a) Qual o momento ideal para realizar essa transformação, tendo em vista que é necessário ter atratividade não só para usuários, mas para clientes?

a) Qual o momento ideal para realizar essa transformação, tendo em vista que é necessário ter atratividade não só para usuários, mas para clientes?

A questão permite distinguir os dois públicos-alvo do empreendimento (visitantes e anunciantes) e a consequente necessidade de estratégias de atratividade dirigidas a cada um deles. Inicialmente, o professor pode estimular a reflexão sobre os atributos interessantes a cada um dos públicos, confrontando-os com os atributos que já se encontram implantados na empresa.

O SEBRAE - Serviço Brasileiro de Apoio às Micro e Pequenas Empresas (2005) enumera algumas características convidativas aos visitantes de negócios virtuais, tais como, comodidade e beleza, bom atendimento, interesse em satisfazer, diferenciação, personalização, confiança e credibilidade, crédito e facilidade de pagamento, serviços adicionais, valorização do cliente, flexibilidade e adaptabilidade, inovação e o oferecimento de garantias. Já os anunciantes buscam grande visibilidade, portanto, o site se tornará atrativo para eles à medida que evidenciar um alto tráfego (TORRES; COZER, 2000).

ARAUJO, M. C. B.; TEIXEIRA, A. A.;FREITAS, A. A. F. Caso de ensino: Um negócio na internet bom pra cachorro. Revista de Empreendedorismo e Gestão de Pequenas Empresas, v.2, n.3, 2013. 
Finalmente, pode-se ressaltar a importância de definir corretamente a entrada no mercado, pois se os concorrentes o fizerem primeiro, a conquista dessa fatia de mercado poderá ser mais cara (CHLEBA, 1999).

\section{b) Quais aspectos legais devem ser observados no processo de formalização?}

Quanto à formalização da empresa, é importante ressaltar para os alunos que um negócio virtual também demanda obrigações legais. O empreendedor deverá formalizar a empresa, pois sem CNPJ fica impedido de fornecer nota fiscal e garantia. Mas que forma jurídica será adotada pela empresa? Quais as características de cada uma das possíveis formas jurídicas a serem adotadas? Segundo o Código Civil Brasileiro, o empreendedor pode registrar-se como empresário, atuando individualmente, ou como sociedade empresária, no caso de atuação com um ou mais sócios. No caso do registro como empresário, o proprietário assume os riscos do negócio de forma ilimitada, logo, além do capital investido, seu patrimônio pessoal fica disponível para o pagamento de eventuais dívidas. Já no caso da sociedade empresária, apenas a parcela referente ao investimento pode ser utilizada para honrar dívidas, salvo se o empreendedor tenha agido de má-fé. Neste caso, seus bens pessoais também ficam disponíveis para pagar credores.

Para facilitar o processo de legalização de uma empresa, o SEBRAE sistematizou esse processo em oito passos que devem ser seguidos pelos empreendedores: $1^{\circ}$ definir localização e verificar compatibilidade desta junto a Administração Municipal; $2^{\circ}$ escolher 0 tipo de sociedade empresária; $3^{\circ}$ escolher 0 nome da empresa na Junta Comercial ou no Cartório de Registro de Pessoa Jurídica de seu município, examinar se já há registro de nome da marca no Instituto Nacional de Propriedade Intelectual; 4ำ elaborar Contrato Social e outros documentos na Junta Comercial ou no Cartório de Registro de Pessoa Jurídica de seu município; 5o realizar o

ARAUJO, M. C. B.; TEIXEIRA, A. A.;FREITAS, A. A. F. Caso de ensino: Um negócio na internet bom pra cachorro. Revista de Empreendedorismo e Gestão de Pequenas Empresas, v.2, n.3, 2013. 
Cadastro Nacional de Pessoa Jurídica (CNPJ) na Secretaria da Receita Federal, sendo importante conferir na Secretaria da Receita Estadual todos os tributos que farão parte das obrigações da empresa; 6ํㅜ obter o Alvará de Funcionamento junto à Prefeitura, Administração Regional ou na Secretaria Municipal da Fazenda de cada município, se as atividades forem realizadas em domicílio próprio, o alvará de funcionamento é condicionado a uma declaração emitida pelos vizinhos afirmando que tais atividades não causam prejuízos à comunidade; $7^{\circ}$ Cadastramento na Previdência Social; $8^{\circ}$ Conseguir o Aparato fiscal na Secretaria de Estado da Fazenda que é responsável pela autorização de impressão das notas e dos livros fiscais. No caso de estudo em questão, como a atividade de marketing do portal faz parte da área de atuação privativa da Administração, a empresa também tem obrigação legal de ter registro no Conselho Regional de Administração. O SEBRAE recomenda a contratação de um contador para auxiliar nos trâmites legais do caso.

2. Além da utilização da publicidade como fonte de receita para a futura empresa, seria viável a venda de produtos pelo portal? Vale ressaltar que pet shops também se enquadram como futuros clientes do portal.

Aqui pode ser requisitada aos alunos a produção de argumentos a favor e contra a realização da venda de produtos através do portal em conjunto com a publicidade de produtos e serviços como fontes conjuntas de receita para a empresa. O aumento da receita da empresa e a possibilidade de desenvolvimento de uma marca própria podem ser apontados como argumentos a favor. Já o fato de uma possível concorrência com os produtos e serviços anunciados ser vista de forma negativa pelos anunciantes e a demanda de capital para o aluguel ou compra de prédio para depósito de mercadoria e para a contratação de serviços de entrega, dados os recursos escassos, constituem contra-argumentos.

ARAUJO, M. C. B.; TEIXEIRA, A. A.;FREITAS, A. A. F. Caso de ensino: Um negócio na internet bom pra cachorro. Revista de Empreendedorismo e Gestão de Pequenas Empresas, v.2, n.3, 2013. 
Essa questão também oferece a possibilidade de estimular o debate entre os alunos sobre a escolha de modelos de negócios virtuais. Felipini (2011) divide os modelos de negócios na internet em três tipos: comerciante, publicidade e corretagem. De uma forma geral, o modelo do comerciante envolve negócios exclusivamente virtuais ou que também possuem uma loja física e que se dedicam à comercialização de serviços ou produtos tangíveis ou virtuais. Já o modelo de publicidade engloba sites que oferecem produtos ou serviços gratuitamente a fim de reunir um grande número de usuários, que compõem potenciais compradores dos anunciantes, constituindo a fonte de receita do site. Finalmente, o modelo de corretagem se refere a sites que aproximam fornecedores e compradores, possibilitando a realização de transações.

Segundo dados do IBGE - Instituto Brasileiro de Geografia e Estatística, através de sua Pesquisa Mensal de Empregos datada de junho de 2011, há um milhão e meio de desocupados (sem emprego ou trabalho) nas principais regiões metropolitanas do Brasil. O emprego formal, com carteira assinada e benefícios vem sendo gradualmente substituído pelo trabalho, ocupação sem vínculo empregatício e de caráter temporário. É importante frisar que até mesmo quem consegue um emprego, não tem mais garantia alguma de estabilidade. Diante dessa realidade enfrentada não só no Brasil, mas no mundo todo, é preciso buscar novas alternativas, perceber novos nichos no mercado. A internet, por ser um setor em intensa expansão e evolução, é uma boa oportunidade para iniciar um empreendimento.

Para iniciar um negócio na internet é preciso estar ciente de alguns aspectos relevantes do processo. Deve-se ter um capital inicial, que na maioria dos casos, é considerado baixo, mas acima de tudo estar preparado para que no prazo de pelo menos um ano, toda ou a maior parte da receita obtida seja reinvestida no empreendimento. É importante conhecer o meio em que o negócio está inserido, contudo a falta de conhecimento técnico mais aprofundado em informática não é um fator restritivo para alcançar o mercado. Se tiver experiência no ramo a ser trabalhado,

ARAUJO, M. C. B.; TEIXEIRA, A. A.;FREITAS, A. A. F. Caso de ensino: Um negócio na internet bom pra cachorro. Revista de Empreendedorismo e Gestão de Pequenas Empresas, v.2, n.3, 2013. 
já se terá uma economia de tempo de aprendizado. Contudo, o mais importante é realmente gostar do ramo escolhido para poder obter o sucesso tão esperado.

3. Apesar de em pouco tempo de inserção no meio, o portal já contém um elevado nível de acessos mensais, contudo o mercado exige um maior número de visualizações. Dentro das limitações financeiras dos idealizadores, que estratégias de marketing digital seriam necessárias para tornar o portal mais acessado?

De acordo com Kendzerski (2009), o marketing digital consiste em ações planejadas que devem sevem ser feitas pelas empresas para ampliar os negócios de forma sustentada, tendo a segmentação, a mobilidade e a interatividade como fatores para obtenção de sucesso na web. O autor defende ainda que, uma empresa com uma estratégia de marketing digital bem aplicada, mesmo que não possua marca conhecida e nem disponha de altos investimentos, pode se destacar no mercado e conquistar uma grande parcela de consumidores, que estão se tornando cada vez mais conscientes e voltados para o ambiente online.

Vaz (2010) apresenta os quatro pilares do marketing digital, que se apoiam no grau de atividade do consumidor para gerar transações comerciais lucrativas. São eles:

- Encontrabilidade - É imprescindível ser encontrado em sites de busca e em redes sociais. Além disso, é necessário que o link seja desperte a atenção do consumidor e que o site seja capaz de retê-lo.

- Usabilidade - O site deve ser de fácil utilização, primando pela simplicidade e pela assertividade.

- $\quad$ Credibilidade - Uma imagem positiva da empresa deve ser cultivada e propagada. As redes sociais cumprem bem esse papel, pois os consumidores crêem nas opiniões de outros consumidores do que na própria empresa.

ARAUJO, M. C. B.; TEIXEIRA, A. A.;FREITAS, A. A. F. Caso de ensino: Um negócio na internet bom pra cachorro. Revista de Empreendedorismo e Gestão de Pequenas Empresas, v.2, n.3, 2013. 
Vendabilidade - O site deve fornecer informações de forma clara e persuasiva.

Além de discutir essas questões, o professor pode estimular a criatividade dos alunos sobre ações de divulgação mais econômicas. Pode ser sugerida a permuta de links com empresas afins; o patrocínio a empresas, produtos ou sites; aproximar-se da mídia a fim de que sejam realizadas matérias sobre o site, dentre outras. Também cabe ressaltar a continuidade das ações já implementadas pela empresa como a presença nas redes sociais.

4. Devido às vantagens de acessibilidade proporcionadas pela internet, o portal já alcançou visibilidade nacional, portanto, caso a publicidade seja escolhida como meio de atuação da empresa, a contratação dos serviços do site, tornar-se-á interessante para anunciantes de todo o país. a) Nesse caso, quais seriam as melhores estratégias para a prospecção de clientes?

Torres e Cozer (2000) apontam algumas alternativas para a prospecção de clientes. Primeiramente, a abertura para anunciantes pode ser divulgada no próprio site, em links como "anuncie aqui" e "informações para anunciantes". Outra possibilidade seria o envio de e-mails para uma lista de anunciantes em potencial. Também podem ser enviados e-mails a agências de publicidades, já que as grandes empresas, geralmente, as contratam para coordenar esse tipo de serviço. Em todos esses casos, cabe lembrar a necessidade de esclarecer qual é o público-alvo do site, bem como suas estatísticas completas (ex.: o número de visitantes, o número total de visualizações, o número de visualizações da página principal).

5. Mesmo restringindo seu nicho de mercado, especializando-se em cães, o portal atua no ramo de publicidade na internet, por isso apresenta vasta

ARAUJO, M. C. B.; TEIXEIRA, A. A.;FREITAS, A. A. F. Caso de ensino: Um negócio na internet bom pra cachorro. Revista de Empreendedorismo e Gestão de Pequenas Empresas, v.2, n.3, 2013. 
concorrência. Que estratégias o portal poderá utilizar não só para se inserir, mas para manter-se no mercado?

Para a inserção no mercado, é imprescindível a alocação de profissionais qualificados, dedicados exclusivamente ao empreendimento, verba de comunicação para planejamento e execução, estratégias bem definidas e sistemas de informação que garantam o atendimento às necessidades dos clientes (CHLEBA, 1999). Já para se manter no mercado, o autor recomenda a atenção às novas tecnologias e aos novos modelos de negócio.

Essa questão também permite que sejam trabalhados alguns conceitos de estratégia. Johnson, Scholes e Whittington (2011) apresentam as estratégias de vantagem competitiva e os modos de sustentar a vantagem competitiva ao longo do tempo, que estão resumidos abaixo e que podem ser discutidos em sala.

\section{Bases de estratégia competitiva}

- $\quad$ Estratégias de preço: Uma opção que pode ser adotada é a combinação de baixo preço com o oferecimento de poucos benefícios de produtos e serviços e foco num segmento de mercado sensível a preços. Também se pode oferecer um preço mais baixo que os concorrentes e, ainda assim, manter os benefícios de produtos e serviços percebidos de maneira similar aos competidores.

- Estratégias de diferenciação: Segundo essa estratégia, pode-se oferecer produtos e serviços superiores pelo mesmo preço praticado pela concorrência ou podese praticar preços levemente mais altos e aumentar os rendimentos.

- Estratégia híbrida: Consiste em proporcionar produtos e serviços otimizados a baixos preços e, ao mesmo tempo, conseguir rendimentos suficientes para reinvestimento a fim de manter e desenvolver novas bases de diferenciação.

ARAUJO, M. C. B.; TEIXEIRA, A. A.;FREITAS, A. A. F. Caso de ensino: Um negócio na internet bom pra cachorro. Revista de Empreendedorismo e Gestão de Pequenas Empresas, v.2, n.3, 2013. 
- Foco: Esta estratégia busca fornecer benefícios altamente percebidos de produtos e serviços para um segmento seleto de mercado de forma a justificar um preço substancialmente diferente.

\section{Sustentação da vantagem competitiva}

- Sustentando a vantagem baseada no preço: Para sustentar a vantagem competitiva baseada em preço a organização pode operar com margens de lucro mais baixas, com uma estrutura de custo exclusiva e também pode trabalhar capacidades específicas da organização e focar em segmentos cujo fator preço baixo é valorizado pelos clientes.

- $\quad$ Sustentando a vantagem baseada na diferenciação: A vantagem baseada em diferenciação pode ser mantida através da criação de dificuldades de imitação e da manutenção de custos inferiores aos dos concorrentes.

- O lock-in estratégico: Pode ser adotado tanto para a sustentação de estratégias baseadas em preço como em diferenciação. O lock-in estratégico ocorre quando a organização alcança uma posição exclusiva em seu setor.

- Reação à ameaça da concorrência: A preservação da vantagem competitiva nas situações em que os concorrentes lançam mão de estratégias competitivas diversas, a organização deve tentar entender o mercado e, a partir disso, criar novas possibilidades de atuação.

Finalmente, também podem ser discutidas questões acerca da temática da fidelização. A fidelidade dos clientes pode ser alcançada através do trabalho sobre a percepção do cliente em relação à empresa, identificando os fatores que geram satisfação (CHLEBA, 1999). O autor também destaca a importância da empresa atender prontamente às sugestões e reclamações e criar um sistema de premiação por meio de pontuação. Logo, a loja virtual implantada pelo site é um ponto forte no que

ARAUJO, M. C. B.; TEIXEIRA, A. A.;FREITAS, A. A. F. Caso de ensino: Um negócio na internet bom pra cachorro. Revista de Empreendedorismo e Gestão de Pequenas Empresas, v.2, n.3, 2013. 
tange à fidelização dos visitantes e deve continuar sendo desenvolvida. No que concerne à fidelização dos anunciantes, é fundamental que haja um acompanhamento estratégico a fim de manter o anunciante a par das estatísticas, ter uma boa ferramenta de gerenciamento de anúncios e demonstrar que o veículo está participando ativamente da campanha de divulgação (TORRES; COZER, 2000).

\section{Referências:}

BRASIL. Novo Código Civil. Lei ㄲo 10.403 de 10 de janeiro de 2002. Brasília, DF, 2002.

CETIC.br. Pesquisa sobre Uso das Tecnologias da Informação e Comunicação no Brasil 2009 <http://www.cetic.br/tic/2009/index.htm>. Acesso em: 20 de julho de 2011.

CHLEBA, M. Marketing digital: novas tecnologias \& modelos de negócio. São Paulo: Futura, 1999.

COMPANHIA, Comissão de Animais de. Pesquisa Radar Pet avalia o perfil e o comportamento dos donos de animais de companhia no Brasil. WSPA Brasil, Rio de Janeiro, ago. 2009. Disponível em: <http://www.wspabrasil.org/latestnews/2009/Pesquisa- Radar-Pet-2009.aspx>. Acesso em: 23 de julho de 2011.

FELIPINI, D. ABC do e-commerce: os quatro segredos de um negócio bemsucedido na internet. Disponível em: <http://www.e-commerce.org.br>. Acesso em: 20 de julho de 2011.

FELIPINI, D. Oportunidades de negócios na internet. Disponível em: http://www2.ciashop.com.br/lebooks/product.asp?template_id=130\&partner_id=74\&dept _id=10\&pf_id=14. Acesso em: 15 jul. 2011.

ARAUJO, M. C. B.; TEIXEIRA, A. A.;FREITAS, A. A. F. Caso de ensino: Um negócio na internet bom pra cachorro. Revista de Empreendedorismo e Gestão de Pequenas Empresas, v.2, n.3, 2013. 


\section{REVISTA}

\section{REG \\ Revista de Empreendedorismo \\ e Geståo de Pequenas Empresas

IAB BRASIL. Indicadores de Mercado de Mídia Digital $<$ http://www.iabbrasil.org.br/arquivos/doc/Indicadores/Indicadores-de-Mercado-IABBrasil.pdf> . Acesso em: 23 de julho de 2011.

IBGE. Indicadores IBGE - Pesquisa Mensal de Empregos, junho de 2011. http://www.ibge.gov.br/home/estatistica/indicadores/trabalhoerendimento/pme_nova/pm e_201106pubCompleta.pdf Acesso em: 20 de julho de 2011.

JOHNSON, G.; SCHOLES, K.; WHITTINGTON, R. Fundamentos de estratégia. Tradução: Rodrigo Dubal. Porto Alegre: Bookman, 2011.

KENDZERSKI, P. Web Marketing e Comunicação Digital. Porto Alegre, Impressão RR Donnelley Moore, $2^{\mathrm{a}}$ Ed., 2009.

NASCIMENTO, R. M. E-commerce no Brasil: Perfil do Mercado e do E-consumidor Brasileiro. Dissertação de Mestrado, EBAPE/FGV, 2011.

PALMA, Consultoria. Histórico do mercado no mundo. PetBR, 2002. Disponível em: <http://www.petbr.com.br/cons14.asp>. Acesso em: 20 de julho de 2011.

SEBRAE. Comece certo: loja virtual. 2005. Disponível em:

http://www.sebrae.com.br/customizado/inovacao/tecnologia/mundo-digital/comercio eletronico/comece-certo-2013-loja-virtual. Acesso em: 19 jul. 2011.

SEBRAE. Agência de Marketing Digital - Exigências legais específicas < http://www.sebrae.com.br/momento/quero-abrir-um-negocio/que-negocioabrir/ideias/integra_ideia?id=F12342CBD8EFCB8F832577AC00728F65\&campo=exigen cias>. Acesso em: 23 de julho de 2011.

TORRES, G.; COZER, A. Alavancando negócios na internet. Rio de Janeiro: Axcel Books, 2000.

VAZ, C. A. Google marketing: o guia definitivo do marketing digital. 3. ed. São Paulo: Novatec editora, 2010.

ARAUJO, M. C. B.; TEIXEIRA, A. A.;FREITAS, A. A. F. Caso de ensino: Um negócio na internet bom pra cachorro. Revista de Empreendedorismo e Gestão de Pequenas Empresas, v.2, n.3, 2013. 
VIOTTO, F. R. Tendências do Mercado PET no Brasil e no Mundo $<$ http://www.abz.org.br/publicacoes-tecnicas/anais-zootec/palestras/22246-TendênciasMercado-PET-Brasil-Mundo.html>. Acesso em: 23 de julho de 2011.

Caso recebido em: 12/08/2013. Aprovado em: 30/12/2013. 